are factors not included in the reckoning, but the adoption by the Board of a chart in which the fishing-grounds of western Europe are divided into "regions" and the North Sea into " areas," according to depth, is excellent, especially in connection with plaice and other flat fishes. In briefly noticing the nature of each area, it is stated that the fishes caught in the North Sea no longer constitute the predominant quantity of a few years ago, but rather more than half the total quantity of "demersal" fishes landed by British vessels, yet the reader is left in doubt concerning the nature of the statistics of a few years ago, and as to whether the recent statistics of the International Bureau have been taken into account. It is interesting that the most prominent fish is the haddock, as in Scotland, a fish about which as many misgivings have been bruited as about the plaice.

On the whole, the report, its foreign and colonial information, and its elaborate, skilfully arranged and important tables, ought to assuage unnecessary fears as to the yield of the sea. It is true statistics are at most approximative, and need the support of scientific experience and a thorough acquaintance with the waters in, as well as adjacent to, the North Sea, both of which were absent, for instance, in the statistics laid by the Scotch Board before the Parliamentary Committee under Mr. Marjoribanks in 1893 , but they are indispensable. In all probability the Board will arrange for a more expeditious issue of the report in future. 'The Scotch Board's report for 1907 is now in hand.

Little need be said about the special report on plaice, by Captain W. Masterman, further than that in its present stage it demonstrates the ability and infinite pains taken by its author in the methods of weighing and measuring specimens from the various "areas" of the North Sea. Four "ichthyometric" ports have been chosen, viz. Grimsby, Boston, Lowestoft, and Ramsgate, and the series of elaborate tables giving the number of large, medium, small, undistinguished and others, from each area, and also their condition as to the viscera, show that every available fact will be grasped. In future reports, no doubt, a record from each area, and from personal observation, of the captures of plaice under $19 \mathrm{~cm}$. which have been thrown overboard before returning to land, will be given, for such would be invaluable in placing the whole subject before the investigator. The use of the smallmeshed ground-net of St. Andrews and the various surfaceand mid-water nets on each area will probably also add further information. The reported fall from 48 million kilos. in 1903 to 29 million kilos. in 1906 merits full investigation. A careful summary of the captures of plaice from the North Sea by other nations would also be useful, especially as Dr. Kyle has shown that the totals of plaice landed at all the North Sea ports were nearly doubled between 1892 and 1903 , and that, ten years after Dr. Petersen had reported the gradual decline of the Danish plaice-fishery in the Cattegat, not only was it more productive, but, as if to emphasise the lesson, an entirely new plaice-fishery by the Swedes on the northern border of the same area had sprung up and was flourishing. Experience demonstrates that when much harrassed and their ranks thinned, the older plaice become, like other fishes, extremely wary, but the vast swarms of very young plaice have shown no diminution on any shore, for it was pointed out long ago ( 1884 ) that none occur in deep water. Even a small untrawlable area is of importance in such a question, and it is stated that, in regard to plaice, I7 per cent. of the area of the North Sea is so. Much information may also be procured by the use of plaice-nets on suitable grounds, especially if diminution is reported. Moreover, the misunderstanding of the Scotch Department in summarising the ten years' work of the Garland should be borne in mind. The whole question is so complex that any new facts obtained by the able scientific staff of the English Board would be very welcome.

The third and very important report is that of the committee on the scientific and statistical investigations, and the task was one which even the special experience of a long life may well have faced with diffidence; yet the fact that the secretary of the commission was the only one specially trained on the subject may have had its advantages, since unbiassed minds would thus be brought to bear on the complex question. In this brief notice, however, it is only possible to make a few general comments, and to allude to the main features of the recommendations-premising that the report, in its comprehensive nature, moderation, and fairness, is worthy of the committee.

In the interesting historical summary of scientific fisheries' work ample justice is done to England, but it is not shown with sufficient clearness that it is to Lord Dalhousie's Commission $(1883-5)$ that the country owes the scientific and statistical initiative in the department, and that ever since such work has been as conspicuously Scotch as English. Further, that many of the recommendations in that report (1884-5) have been utilised by the Scotch, English, and Irish Boards-in some cases for many years, whilst others are again brought up in the present report. Amongst other things, it is curious that the herring-brand of the Scotch Board has apparently been thought more important than the ten years' unique work of the Garland and the scientific conclusions therefrom, and that the work of the recently formed Uister Marine Biological Association is duly noted, whilst the committee appears to be unaware of the existence of the oldest marine laboratory in Britain for scientific fisheries' work. The account of the personnel of the British section of the international investigations and the historical summary might well have been abbreviated. In their outline of future investigations the committee has prudently followed what has previously been advised (minus hydrography and chemistry, both of which are somewhat expensive, whilst the results to the fisheries have been small). Artifioial hatching for the stocking of the sea also is, so far as observed, an unnecessary task.

A central fisheries council, representative of the three divisions of the kingdom, as suggested, has much to recommend it, but it would be well to consider-on the score of efficiency and expense-whether one instead of two members from each division would not suffice, the Treasury appointing the other two, after consultation with the Royal Society, not the Meteorological Office. No fault can be found with the restriction of the labours of the council to researches and statistics affecting the common interests of the sea-fisheries of the United Kingdom, and to the other duties stated, provided due attention is given to uniformity of method in the annual reports of each division. Yet a further step is worthy of consideration, viz. the severance of the Fisheries' Department from agriculture and its representation in Parliament by a responsible Minister, as the minority report so far indicates. In regard to the continuance of the grant of roool. per annum to the Plymouth Laboratory-with the necessary reservations-no dissentient voice will be heard amongst men of science. There can be no question as to the expediency of appointing a scientific officer and scientific assistants to the English Department of Fisheries. It is difficult to explain why this has so long been delayed. Nor is there any objection to the committee's scheme for international cooperation or to the Ir.ternational Council on the lines indicated. The sea is the highway between nations, and to a large extent their common fishing-ground. It is to be hoped that the Government will, in the main, give effect to the committee's judicious recommendations.

W. C. M.

\section{THE EUROPEAN POPULATION OF THE UNITED STATES.}

PROF. RIPLEY, in his Huxley lecture delivered recently before the Royal Anthropological Institute, on the European population of the United States, raised a number of novel and important problems, for the solution of which the evidence is at present insufficient. In contrast to Europe, where the existing races have grown up from the soil, in America they, "one may say, have dropped from the sky. They are in the land, but not yet an integral part of it. They are as yet unrelated to its physical environment." Further, the influence of environment on this diverse population is as yet little more than a matter for speculation. The day has passed for assuming that the modern American type is a reversion to that of the American Indian; but for the future of this foreign population suddenly planted among new surroundings we must 
depend more upon speculation than upon prophecy, because as yet, except in the classical records of the armies recruited in the Civil War, anthropological statistics are not available.

The extent of this foreign invasion of the country is stupendous. Twenty-five million emigrants have landed since 1820 , and in 1907 no fewer than one and a quarter miltion souls were added to the population; and, what is still more remarkable, the source of supply has completely changed in recent years. A quarter of a century ago twothirds of the annual immigration was in origin Teutonic or Anglo-Saxon; at present less than one-sixth is derived from this source. The newcomers are now mainly south Italian, Russian, or Austro-Hungarian. "We have even tapped the political sinks of Europe, and are now drawing large numbers of Greeks, Armenians, and Syrians." Ninety per cent. of the tailors of New York are RussoPolish Jews; all day labourers, once Irish, are now Italian; fruit-vendors, once Italian, are now Greek. Chicago is now the second Bohemian, the third Swedish, the fourth Polish, the fifth German city in the world.

The question then arises, Will these racial groups coalesce into a more or less uniform American type? In dealing with this problem, Prof. Ripley discusses the causes which promote and those which operate to prevent the union of these races. On the one hand, as tending to combination, he notices the extreme mobility of the newer industrial immigrants, and their readiness to wander into the most distant parts of the country in search of employment; the inequality of the sexes, males being in a large majority, which results in marriage of the newcomers with locally born women. In this connection, he remarks the tendency of the male as he rises in the world endeavouring to improve his social position by marrying into a class higher than his own. The main cause which checks further union of the races is the concentration or segregation of the immigrants in compact industrial colonies or in the large cities of the west. While the Teutonic races wander far afield as colonists, the Mediterranean, Slavic, and Oriental races herd in the towns.

An investigation of marriage statistics brings out many interesting facts. Even in the case of the Jews, the most exclusive of peoples, there is more intermarriage than is commonly supposed, the Jews in Boston constantly taking as wives Irish or Irish-American women. All the facts of marriage and birth-rates, however, indicate a relative submercence of the Anglo-Saxon stock in the near future. While the birth-rate among them is steadily declining, the fecundity of the foreign races newly arrived in the country shows little signs of diminishing. In Massachusetts the birth-rate of these two races is in the proportion of about one to three. This superiority will probably not be maintained, as even now the fecundity of the foreigners seems to be diminishing after the second generation; but their vitality under a favourable environment is remarkable.

As Prof. Ripley observes, this race struggle is only in its very earliest stage and it remains to be seen whether the Anglo-Saxon will be able to preserve and transmit his characteristic culture over these hordes of foreigners.

America, including. Canada, is thus confronted with a novel series of problems, racial and social, and to add to these she has to deal with a fresh set of difficulties connected with the Negro and the Filipino, with which Prof Ripley was unable to deal in this address. He cherishes a pious hope that a satisfactory solution will be attained; hut this lies in the lap of the future, and it will be well that this notable address should attrart on both sides of the Atlantic the attention which it descrves.

\section{UNIVERSITY AND EDUCATIONAL INTELIIGENCE.}

CAMBridge.-The general board of studies recommends the appointment of an assistant to the Quick professor of biology. It is proposed that Prof. Nuttall should appoint him with the approval of the Vice-Chancellor; the appointment will terminate on the appointment of a successor to the present professor. It carries with it a stipend of rool. a year.
It is suggested to increase the stipend of the curator of the botanic garden to $35 \mathrm{ol}$. a year. It is now nearly thirty years since the present curator was appointed, and the position the Cambridge Botanic Garden now occupies is largely due to Mr. Lynch's ability and devotion.

Prof. R. C. Maclaunin, professor of mathematical physics in Columbia University, and previously professor of mathematics in the University of New Zealand, has accepted, we learn from Science, the offer of the presidency of the Massachusetts Institute of Technology.

The Chelsea Secondary School for Girls was formally opened on November 20. The school was originally part of the South-Western Polytechnic, and the transfer was effected in September last. The new buildings are situated in Hortensia Road, and represent the first school building expressly designed and erected by the London County Council for the secondary education of girls. The aim of the new school is to provide a liberal education for girls up to the age of eighteen or nineteen years. The claims of science to a prominent place in the school curriculum have been duly recognised, and ample accommodation has been provided for the practical study of chemistry, physics, and botany. The home arts are to be taught, and suitable rooms have been arranged for this purpose, as well as for practical work in geography.

THE report of the principal of the Bradford. Technical College for the session $1907^{-8}$ shows that the total number of students in attendance during the session was virtually the same as in the previous year; but there was, unfortunately, a fall in the number of day students from 242 to 217 . The average age of these students at the commencement of the session was nineteen years, as compared with eighteen years five months at the corresponding period of 1906. We notice that a new scholarship scheme has been adopted during the session. It provides opportunity for the transference of evening students of exceptional ability to the day courses, and offers special scholarships for apprentices in works. In order to carry the specialised training to as high a point as practicable, a number of fourth-year scholarships are offered to day students who have completed their three years' course, and as a recognition of the necessity for securing the best brains and the highest possible preliminary training a certain number of entrance scholarships are awarded on merit alone. The scheme affords evidence of the desire that all sections of the community should have equal facilities, as they have an equal claim to the advantages of the college training. The scheme for building a new block for the accommodation of the department of textile industries on an adjoining site already purchased has taken definite shape; detailed plans are being prepared, and building is to be begun shortly. The staff of the department of chemistry and dyeing has been strengthened with the view of the encouragement of research work in the college. The testing laboratory of the department of textile industries has been employed to a much greater extent than previously in carrying out investigations for the trade. It is pleasing to note that the advantages offered to manufacturers and others are being more fully realised.

\section{SOCIETIES AND ACADEMIES. LONDON.}

Physical Society, November 13.-Dr. C. Chree, F.R.S., president, in the chair.--The photoelectric properties of potassium-sodium alloy: Dr. Fleming. It is well known that, under the action of ordinary and ultra-violet light, the electro-positive metals lose a negative charge of electricity, the effect being most pronounced in the case of rubidium, potassium, and the liquid alloy of potassium-sodium. Potassium and sodium are melted together and then decanted over into a chamber containing a platinum plate, so that a mass of the liquid potassium-sodium alloy having a perfectly clean surface was obtained in a glass tube, and a platinum plate was fixed above it in an inclined position. 